\title{
Fracture toughness of TiAl-Cr-Nb-Mo alloys produced via centrifugal casting
}

\author{
A. Brotzu, F. Felli, D. Pilone \\ Dipartimento ICMA, Sapienza Università di Roma, Via Eudossiana 18, 00184 Roma (Italy)
}

\begin{abstract}
Fracture toughness of a TiAl base intermetallic alloy has been investigated at room temperature. The Ti-48Al-2.5Cr-0.5Nb-2Mo (at. \%) alloy produced via centrifugal casting exhibits fine nearly lamellar microstructures, consisting mainly of fine lamellar grains, together with a very small quantity of residual $\beta$ phases along lamellar colony boundaries. In order to determine the alloy fracture toughness compact tension specimens were tested and the results were compared with those available in literature.
\end{abstract}

KEYWORDS. Titanium aluminides; Fracture toughness; Intermetallics.

\section{INTRODUCTION}

G amma titanium aluminides are considered to have great potentials in high temperature applications, mainly due to weight saving in combination with excellent mechanical properties at elevated temperatures [1-3] and good resistance to high temperature oxidation when alloying elements are carefully selected [4, 5]. However, their applications are hindered by relatively low room temperature ductility, poor fracture toughness and bad hot workability. In the last decades, significant improvements in the room temperature ductility and fracture toughness of these alloys have been achieved by a careful selection of alloying elements, heat treatments and thermomechanical treatments [6-9]. Over the last years $\beta$ phase containing alloys have been developed and studied due to their good hot deformability. In fact the disordered $\beta$ phase structure is softer than $\alpha_{2}$ and $\gamma$ phases at high temperature and then it aids thermomechanical processing of TiAl alloys [10].

Among several kinds of alloys TiAl alloys combining $\alpha_{2}$ and $\gamma$ phases show reasonable fracture toughness: after forging and heat treatment the $\mathrm{K}_{\mathrm{IC}}$ reaches a value of about 30 [11,12]. Studies available in literature show that in lamellar structures the local resistance to crack propagation depends on the lamellae orientation. Fracture toughness tests gave toughness values ranging from 3.5 to 25.7 [13]. A new class of TiAl alloys showing an interesting balance of properties has been recently developed and obtained by thermal treating cast TiAl alloys. In these alloys each grain contains $\alpha_{2}$ lamellae embedded in $\gamma$, creating a "convoluted" structure [14]. One of these novel alloys displays fracture toughness values of 13 at room temperature and 19 at $923 \mathrm{~K}$.

Considering the bad workability of TiAl intermetallic alloys, toughness tests are often carried out according to the ASTM E1820 standard by using samples tested in 3-point bending.

In this work the authors explored fracture toughness and tensile strength of the Ti-48Al-2.5Cr- $0.5 \mathrm{Nb}-2 \mathrm{Mo}$ (at. \%) alloy produced via centrifugal casting and set up a methodology to obtain compact tension specimens via direct centrifugal casting. 


\section{EXPERIMENTAL}

A $\mathrm{n}$ alloy having the nominal composition Ti-48Al-2.5Cr- $0.5 \mathrm{Nb}-2 \mathrm{Mo}$ (at. \%) was prepared by induction melting under an $\mathrm{Ar}$ atmosphere from pure $\mathrm{Ti}, \mathrm{Al}, \mathrm{Cr}$ and $\mathrm{Nb}$. The molten metal was cast directly into the rotating mould. Microstructure and mechanical properties of castings are affected by melting temperature and rotation speed of the mould. In this experimental work the mould rotation speed was $1500 \mathrm{rpm}$ for all the specimens. As far as the melting temperature is concerned, because of the geometry of the used induction furnace and because of the poor precision of the optical pyrometer it was not possible to fix a casting temperature but we proceeded to carry out the casting 30 seconds after the complete melting of the charge material. The melting process was observable through a quartz window facing the ceramic crucible. Metallographic specimens were prepared using conventional methods and were etched with the Keller's reagent to reveal the grain structure. Metallographic structure was inspected by both optical microscope and scanning electron microscope (SEM) and microanalyses were carried out by energy dispersion spectroscopy (EDS). Phases were examined by X-ray diffraction (XRD).

The tensile and CT specimens, whose average composition is reported in Tab.1, were produced by means of centrifugal casting using a graphite mould: graphite cores were used to obtain the holes.

\begin{tabular}{lccccc}
\hline & $\mathrm{Al}($ at.\%) & $\mathrm{Ti}($ at.\%) & $\mathrm{Cr}$ (at.\%) & $\mathrm{Nb}$ (at.\%) & Mo (at.\%) \\
Specimen 1 & 48.83 & 45.88 & 2.81 & 0.58 & 1.90 \\
Specimen 2 & 47.80 & 47.54 & 2.05 & 0.35 & 2.28 \\
Specimen 3 & 47.32 & 47.31 & 2.66 & 0.54 & 2.17 \\
Specimen 4 & 47.85 & 46.62 & 2.84 & 0.47 & 2.21 \\
\hline
\end{tabular}

Table 1: Average composition of the CT specimens.

Fig. 1 shows the obtained ingot. The average dimension are: thickness $9.7 \mathrm{~mm}$, width $33 \mathrm{~mm}$, length $40 \mathrm{~mm}$, distance between the centre of the holes $14.3 \mathrm{~mm}$, hole diameter $5.7 \mathrm{~mm}$. The upper portion of the ingots, where the shrinkage cone is located, has been removed and a crack has been obtained by using a diamond blade. Fracture toughness testing was carried out in general accordance with ASTM E399 using an Instron-3367 instrument with a cross-head speed of 0.5 $\mathrm{mm} / \mathrm{min}$. Load and displacement data were recorded during the tests and the fracture strength $P_{\max }$ was calculated from the obtained curves. Fracture surfaces were analysed by SEM in order to evaluate fracture mode and fracture sites. After toughness test $2 \mathrm{~mm}$ thick slices were cut from CT specimens. These slices were machined in order to obtain small non proportional dog bone tensile specimens with rectangular section. The calibrated zone length was about $10 \mathrm{~mm}$ with a rectangular section area $S_{0}$ of about $15 \mathrm{~mm}^{2}$. Tensile tests were carried out in general accordance with ASTM E8 M and UNI EN 10002-1 using an Instron 3367 instrument (cross-head speed of $0.5 \mathrm{~mm} / \mathrm{min}$ ).

Hardness tests have been carried out by using a Wolpert hardness tester with a Vickers diamond pyramidal indenter.

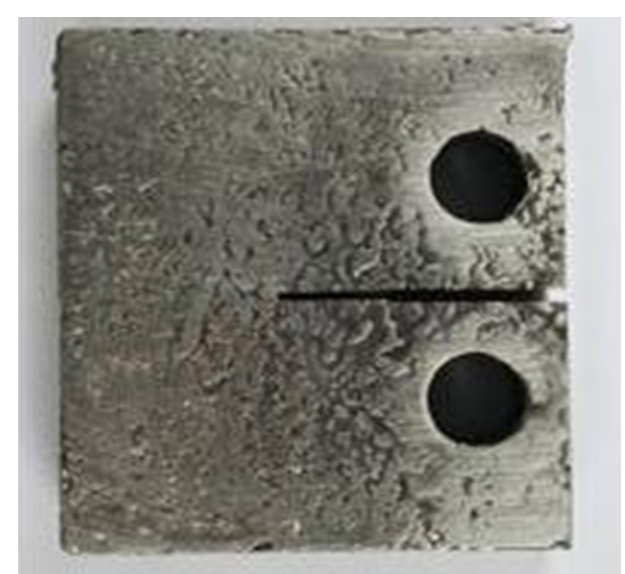

Figure 1: Macrograph showing the CT specimen. 


\section{RESULTS AND DISCUSSION}

I ngots produced by centrifugal casting were analysed by means of optical and electron microscopy (SEM / EDS) in order to evaluate their composition and structure. Analyses revealed that the different castings have a very similar composition and that are characterized by the presence of shrinkage microporosity. The alloy microstructure is fully lamellar (Fig. 2) and it is characterized by grains of alternate $\alpha_{2} / \gamma$ lamellae as shown by the XRD pattern reported in Fig. 3 . SEM analysis highlighted also the presence of a very small quantity of a bright phase in the backscattered image that is a chromium and molybdenum rich phase.

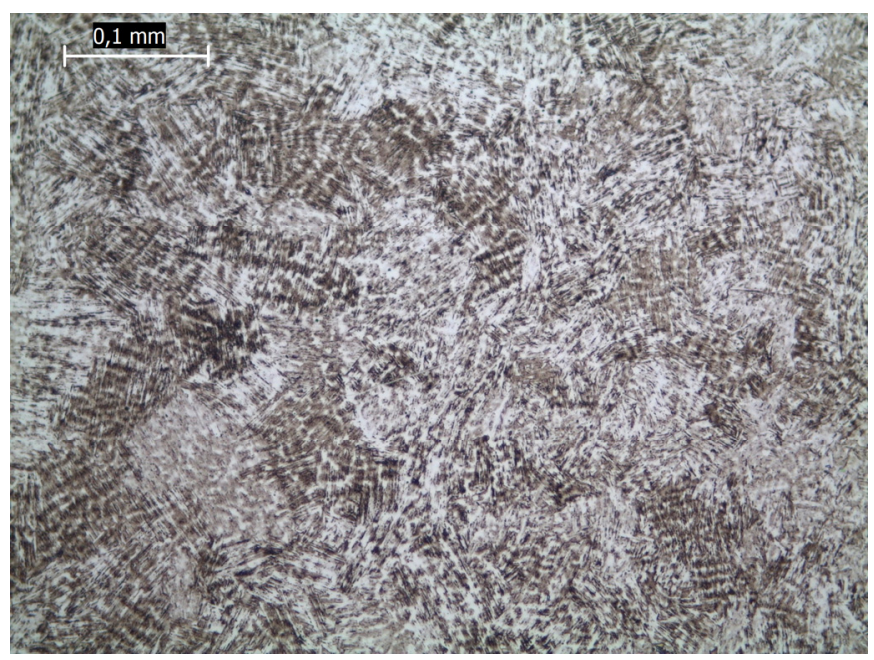

Figure 2: Optical micrograph showing the alloys' microstructure.

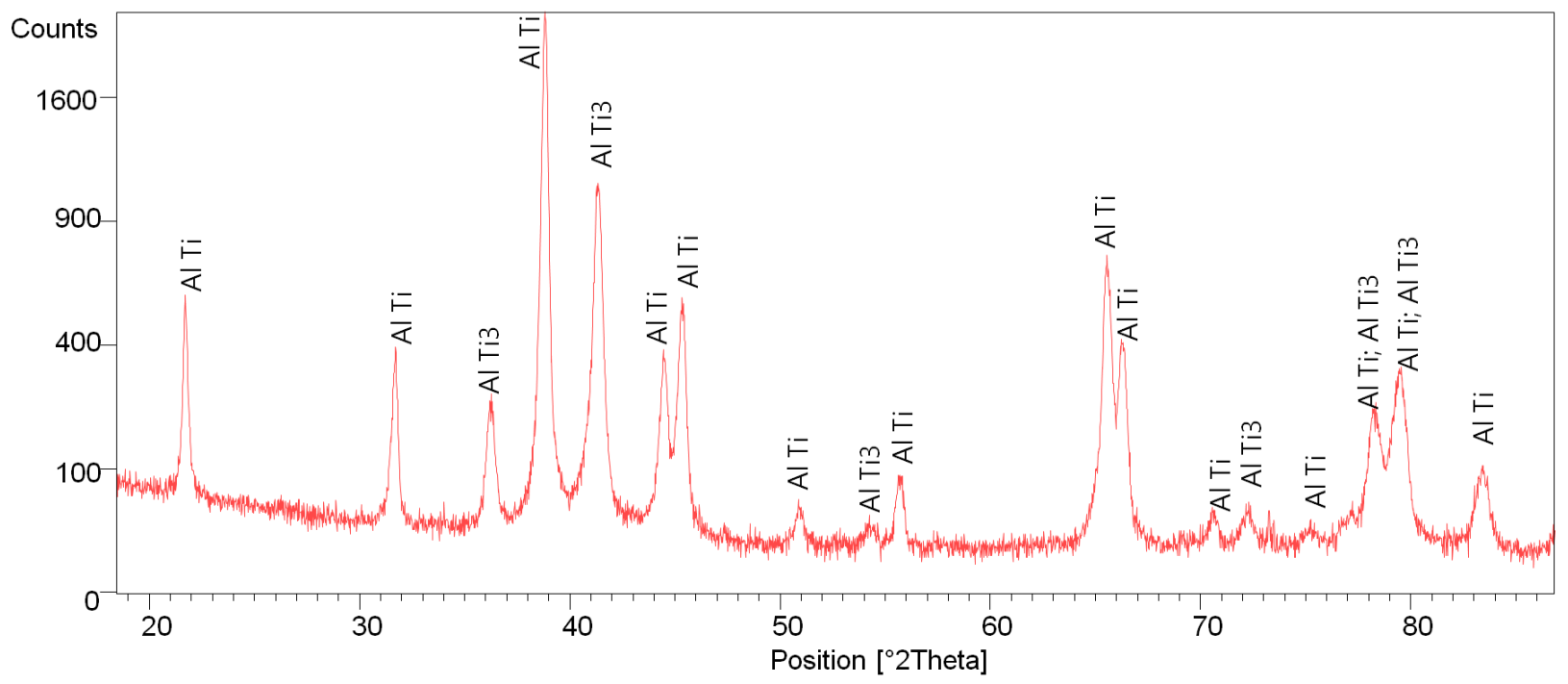

Figure 3: XRD pattern showing the alloy composition.

The studied alloys show a brittle behaviour during tensile tests with a fracture surface inclined at $45^{\circ}$ to the tensile axis. The stress increases continuously without any appreciable plastic deformation up to the maximum stress. The maximum measured value of the ultimate tensile strength was 435.9 MPa. The morphological analysis of the tensile test fracture surfaces points out that the fracture propagates following an integranular path (Fig. 4). Presence of dimples was never observed. The fracture surface is characterized by a lamellar morphology that closely reminds the lamellar microstructure shown in Fig. 2. Hardness tests carried out on those alloys gave hardness values ranging from $436 \mathrm{HV}$ to $510 \mathrm{HV}$. 


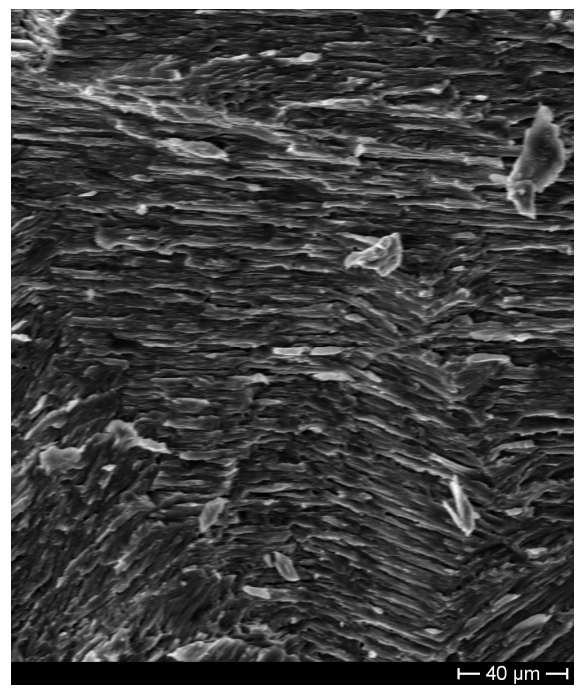

Figure 4: SEM micrograph showing the fracture surface morphology.

In this work four CT specimens were used for toughness tests.

The curves load vs. displacement (Fig. 5) were elaborated according to the ASTM E 399 standard in order to obtain the load values required to calculate the $\mathrm{K}_{\mathrm{IC}}$. All the obtained data are reported in Tab. 2. For all the tested specimens the value of $\mathrm{P}_{5}$ coincides with the value of $\mathrm{P}_{\mathrm{Q}}$ and the ratio $\mathrm{P}_{\max } / \mathrm{P}_{\mathrm{Q}}$, which is the first acceptance criterion established by the ASTM standard, is always lower than 1.10. It is then possible to calculate the $\mathrm{K}_{\mathrm{Q}}$ values. The calculated $\mathrm{K}_{\mathrm{Q}}$ values are: 16.9 $\mathrm{MPa} \sqrt{\mathrm{m}}$ for specimen $1,16.6 \mathrm{MPa} \sqrt{\mathrm{m}}_{\mathrm{m}}$ for specimen $2,15.56 \mathrm{MPa} \sqrt{\mathrm{m}}_{\mathrm{m}}$ for specimen 3 and $23.8 \mathrm{MPa} \sqrt{\mathrm{m}}_{\text {for specimen } 4 .}$

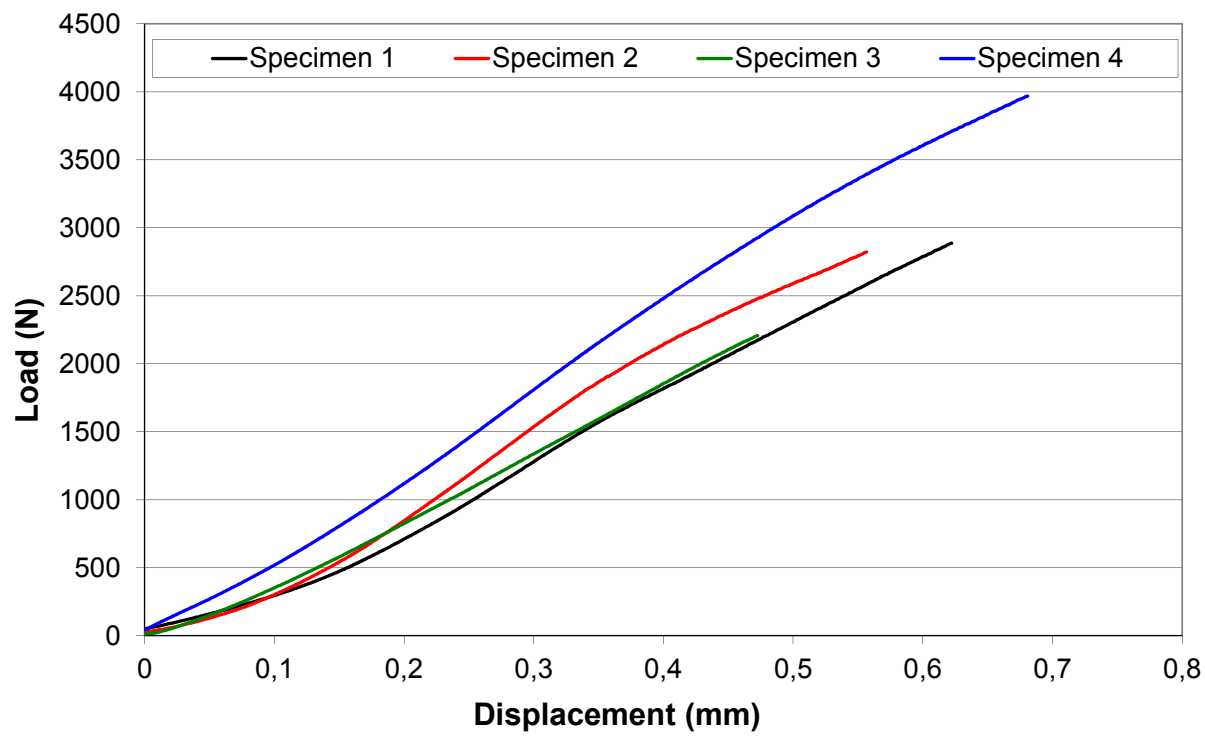

Figure 5: Load versus displacement curves obtained for the four specimens.

\begin{tabular}{lccccc}
\hline & $\begin{array}{c}\mathrm{P}_{\max } \\
(\mathrm{kN})\end{array}$ & $\begin{array}{c}\mathrm{P}_{5}=\mathrm{P}_{\mathrm{Q}} \\
(\mathrm{kN})\end{array}$ & $\begin{array}{c}\mathrm{K}_{\mathrm{Q}} \\
(\mathrm{MPa} \sqrt{\mathrm{m}})\end{array}$ & $\mathrm{P}_{\max } / \mathrm{P}_{\mathrm{Q}}<1.10$ & $\begin{array}{c}\text { Acceptance criteria } \\
\mathrm{R}_{\mathrm{p}}<9.7 \mathrm{~mm}(\mathrm{~B})\end{array}$ \\
Specimen 1 & 2.888 & 2.888 & 16.9 & 1.00 & 3.8 \\
Specimen 2 & 2.822 & 2.800 & 16.6 & 1.01 & 3.6 \\
Specimen 3 & 2.207 & 2.207 & 15.5 & 1.00 & 3.2 \\
Specimen 4 & 3.969 & 3.850 & 23.8 & 1.03 & 7.5 \\
\hline
\end{tabular}

Table 2: Data obtained from the load- crack displacement curves. 
The second acceptance criterion requires that both the thickness B of the CT specimens and the crack length shall be higher than $2.5\left(\mathrm{~K}_{\mathrm{Q}} / \sigma_{\mathrm{YS}}\right)^{2}$ where $\sigma_{\mathrm{YS}}$ is the $0.2 \%$ offset yield strength in tension. Considering that the load-displacement curves obtained do not highlight any plastic deformation, in this formula the ultimate tensile strength was used.

For all the tests these calculated values were lower than the thickness B of the CT specimens and the crack length a. The calculated $K_{Q}$ values can then be considered as $K_{I C}$. The $K_{I C}$ values are close enough and comparable, showing a good reliability of the used methodology. These values are also comparable with those reported in literature [9] for similar alloys and obtained by using samples tested in 3-point bending. These tests were carried out on alloys thermomechanically treated by hot isostatic pressing at $1250{ }^{\circ} \mathrm{C}$ for 4 hours at $175 \mathrm{MPa}$ and aged at $950{ }^{\circ} \mathrm{C}$ for 48 hours in order to eliminate porosity and residual stresses. The fact that the $\mathrm{K}_{\mathrm{IC}}$ values we found are close to those could suggest that the described post-casting treatment is not that effective.

Fig. 6 shows the fracture surface macrographs (a) and the morphology of the fracture surfaces (b). Fig. 6b highlights that the fracture surface is characterised by the typical cleavage fracture morphology where lamellae are well visible.

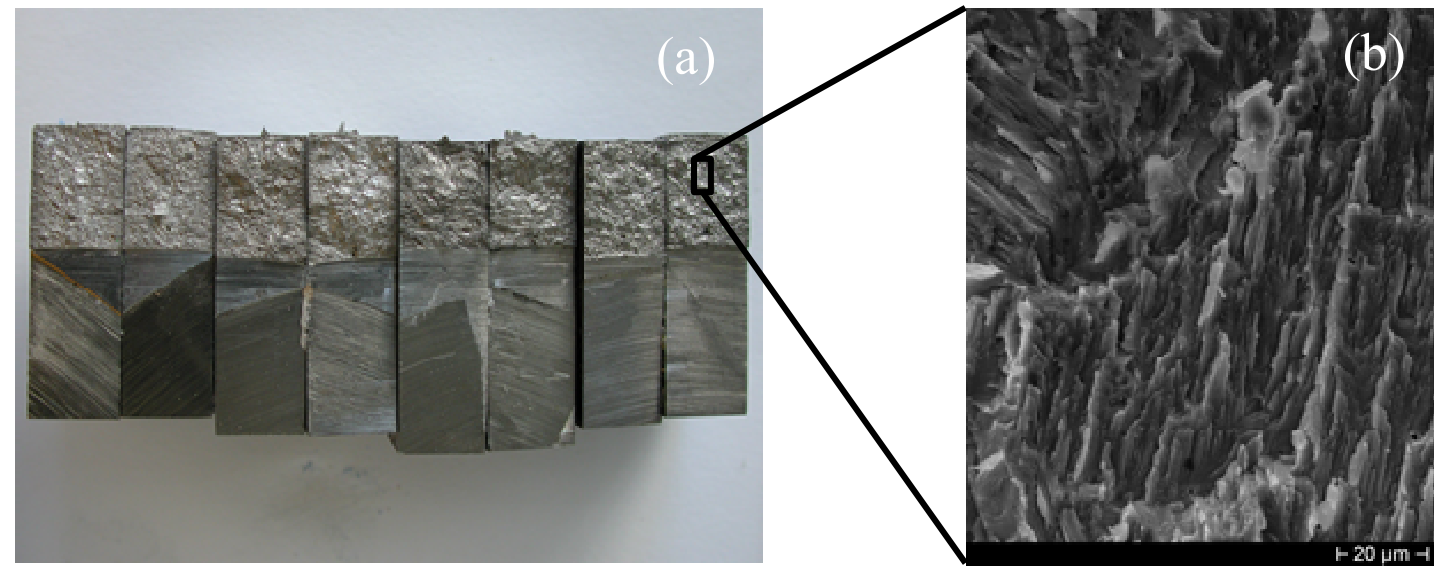

Figure 6: Macrograph showing the fracture surfaces (a) and SEM micrograph showing the fracture surface morphology (b).

\section{CONCLUSIONS}

I $\mathrm{n}$ this work a Ti-48Al-2.5Cr-0.5Nb-2Mo (at. \%) alloy was produced via centrifugal casting in order to evaluate its ascast structure and mechanical properties. The main objective of this work was to set up a reliable methodology to measure the toughness of these alloys by using CT specimens. To this end four CT specimens were cast and tested. The $\mathrm{K}_{\mathrm{IC}}$ values range from 15.5 to 23.8 . This variability is attributable to small changes in melting time and temperature that affect lamellar colony size. The higher ultimate tensile strength was 435.9 MPa.

These results highlight that the $\mathrm{K}_{\mathrm{IC}}$ values obtained for the as-cast structures are acceptable and comparable with data available in literature for similar alloys subjected to thermomechanical treatments. This suggests that the used methodology is reliable and that mechanical properties can be further improved by a careful selection of both alloying elements and thermal treatments.

\section{REFERENCES}

[1] E. A. Loria, Intermetallics, 8 (2000) 1339.

[2] X. H. Wu, Intermetallics, 14 (2006) 1114.

[3] M. Yamaguchi, H. Inui, K. Ito, Acta Mater, 48 (2000) 307.

[4] D. Pilone, F. Felli, Intermetallics, 26 (2012) 36.

[5] D. Pilone, F. Felli, In: TMS Annual Meeting, 3 (2008) 413.

[6] M. H. Loretto, A. B. Godfrey, D. Hu, P. A. Blenkinsop, I. P. Jones, T. T. Cheng, Intermetallics, 6 (1998) 663.

[7] S. Shih Donald, Y. W. Kim, In: Ninomi M, Akiyama S, Ikeda M, editors. Ti-2007 science and engineering [C]. Kyoto, Japan: The Japan Institute of Metals; (2007) 1021.

[8] A. Bartels, H. Kestler, H. Clemens, Mater Sci Eng A, 329-331 (2002) 153. 
[9] Y. Chen, H. Niu, F. Kong, S. Xiao, Intermetallics, 19 (2011) 1405.

[10] T. Toshimitsu, S. Kentaro, K. Satoshi, K. Satoru, T. Masao, Intermetallics, 13 (2005) 971.

[11] K. S, Chan, D. S. Shih, Metallurgical and Materials Transactions A, 28 A(1) (1997) 79.

[12] D. S. Shih, S. C. Huang, G. K. Scarr, H. Jang, J. C. Chesnutt, In: Kim YW, Boyer R, editors. Microstructure/property Relationships in titanium aluminides and alloys. 1990 Fall Meeting of the Minerals. Detroit MI (USA): Metals and Materials Soc; (1991) 135.

[13] S. Yokoshima, M. Yamaguchi, Acta Materialia, 44(3) (1996) 873.

[14] N. Barbi, F. Diologent, R. Goodall, A. Mortensen, Intermetallics, 22 (2012) 176. 